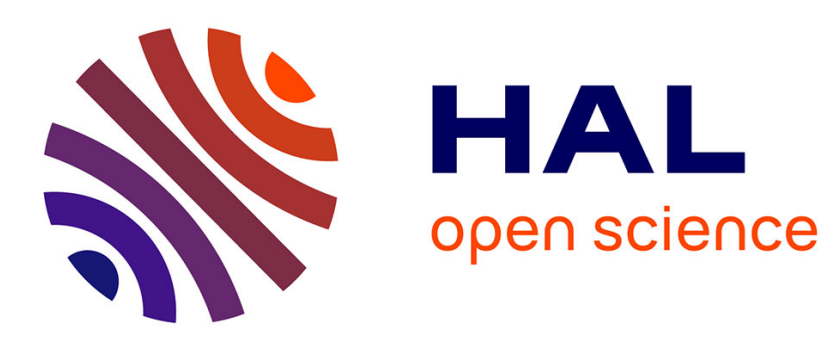

\title{
Investigation of hot salt corrosion at a land-based gas turbine installation
}

F. Starr, N. Wood, R. Robertson

\section{To cite this version:}

F. Starr, N. Wood, R. Robertson. Investigation of hot salt corrosion at a land-based gas turbine installation. Journal de Physique IV Proceedings, 1993, 03 (C9), pp.C9-779-C9-786. 10.1051/jp4:1993981. jpa-00252423

\section{HAL Id: jpa-00252423 https://hal.science/jpa-00252423}

Submitted on 1 Jan 1993

HAL is a multi-disciplinary open access archive for the deposit and dissemination of scientific research documents, whether they are published or not. The documents may come from teaching and research institutions in France or abroad, or from public or private research centers.
L'archive ouverte pluridisciplinaire HAL, est destinée au dépôt et à la diffusion de documents scientifiques de niveau recherche, publiés ou non, émanant des établissements d'enseignement et de recherche français ou étrangers, des laboratoires publics ou privés. 


\title{
Investigation of hot salt corrosion at a land-based gas turbine installation
}

\author{
F. Starr, N. Wood $\left({ }^{1}\right)$ and R. Robertson $\left({ }^{2}\right)$ \\ ( ${ }^{1}$ British Gas plc, Research and Technology, Gas Research Centre, Ashby Rd, Loughborough, \\ U.K. \\ $\left(^{2}\right)$ British Gas plc, St. Fergus Gas Terminal, Peterhead, Aberdeenshire, U.K.
}

\begin{abstract}
Many natural gas-fuelled power plants will be situated close to the sea, where salt spray can result in fouling of compressors, and even hot salt corrosion of the turbine blading. This investigative work was carried out on corroded nimonic 108 blades, from one of British Gas's RB211 engines. It showed that the turbines had been running at too high temperature. This combined with the salt, had caused rapid corrosion of the leading edges and blade shrouds. Alterations to operating procedures, and the recommendation of more resistant coatings has alleviated the problem.
\end{abstract}

\section{Introduction.}

This paper describes work done within British Gas to diagnose a hot section corrosion problem of a land-based RB211 gas turbine, at the St. Fergus gas terminal in Scotland. It describes how the severity of the corrosion resulted from the interaction of a number of factors, and outlines the measures taken to alleviate the problem. The discussion further highlights how hot salt corrosion could be a problem for many gas-fuelled generating systems currently under consideration.

\section{Detection of hot salt corrosion.}

The corrosion problem was detected when staff at St. Fergus inspected the first stage high pressure turbine blades during an annual shut-down, following tests carried out on the effectiveness of the procedure for washing the compressors. The tests had detected trace amounts of metallic ions, typical of those found in turbine blades, in the drainwater. The metallic ions could have originated from soluble salts in corrosion deposits; hence, two blades were sent to LRS for examination.

Visual examination of the blades (Plate 1) revealed a large amount of corrosion on the underside of the blade shrouds, an unusual location for hot corrosion.

Work done by Page and Taylor [1] shows that, normally, most corrosion is spread over the blade surface, or concentrated on the mid-span. 


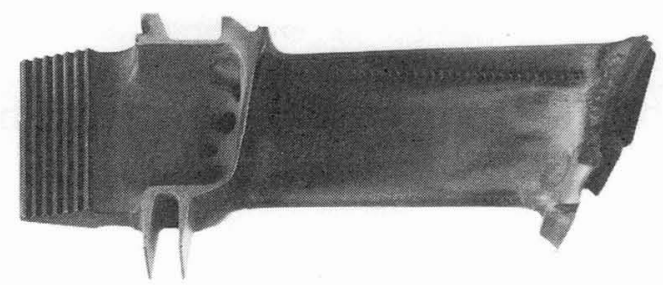

Plate 1. - Photograph of RB211 turbine blade. The blade length is $15 \mathrm{~cm}$.

\section{Outline of investigative work.}

In order to investigate the nature of the corrosion problem, several pieces of work were carried out. First, the corrosion deposits were examined directly, then one turbine blade was cross-sectioned and examined. Most of this work involved use of the SEM.

3.1 BLADE TEMPERATURE ESTIMATIONS. - The RB211 engines at St. Fergus use the wrought superalloy nimonic 108 for their high pressure stage blading, a $\gamma^{\prime}$ strengthened alloy. To obtain a high $\gamma^{\prime}$ content in a nimonic alloy, the chromium level must be kept low [2]. Nimonic 108 has a chromium level in the range 13.5-16 wt. per cent, which makes it susceptible to oxidation and hot corrosion. Hence, the turbine blades used at St. Fergus had been packaluminised.

To evaluate the service history of the blades from the RB211 engines, we carried out some heat treatments of our own, with an unused turbine blade, and then made a comparison. The heat treatment times and temperatures were chosen by making use of the data in figure 1 [2].

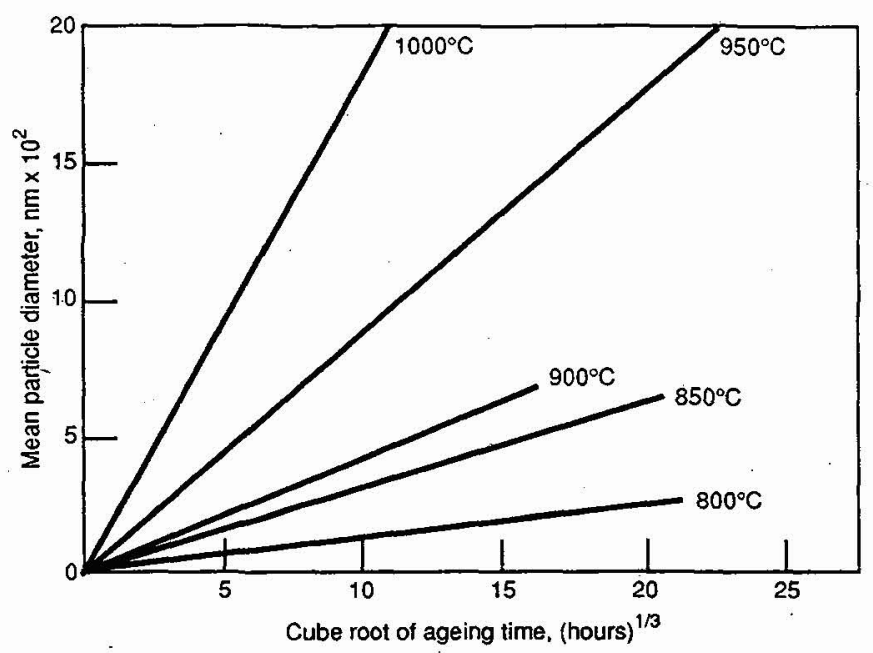

Fig. 1. - Growth curves of $\lambda^{\prime}$ particles in nimonic 105 -solution-treated $4 \mathrm{~h} / 1150^{\circ} \mathrm{C}$, air cool (nimonic 108 is very similar to nimonic $105[2])$. 
One of the turbine blades that had been in service at St. Fergus for about 8000 hours, was sectioned into six parts, and examined in the SEM, in order to check the microstructures. Their micrographs are shown in plates 2a-c. They show how much the $\gamma^{\prime}$ particles had coarsened. We estimated the section in plate $2 \mathrm{a}$ to have run at $925-950^{\circ} \mathrm{C}$, and the sections in $2 \mathrm{~b}$ and $2 \mathrm{c}$ at $900^{\circ} \mathrm{C}$. For comparison, plate $2 \mathrm{~d}$ shows an "as-received" structure of nimonic 108.

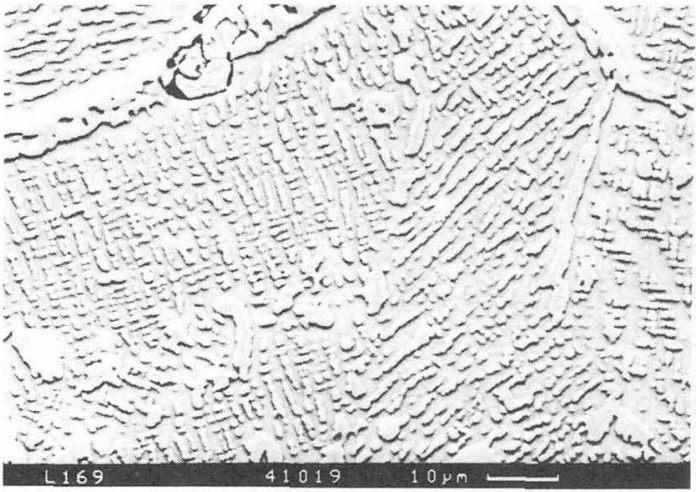

a)

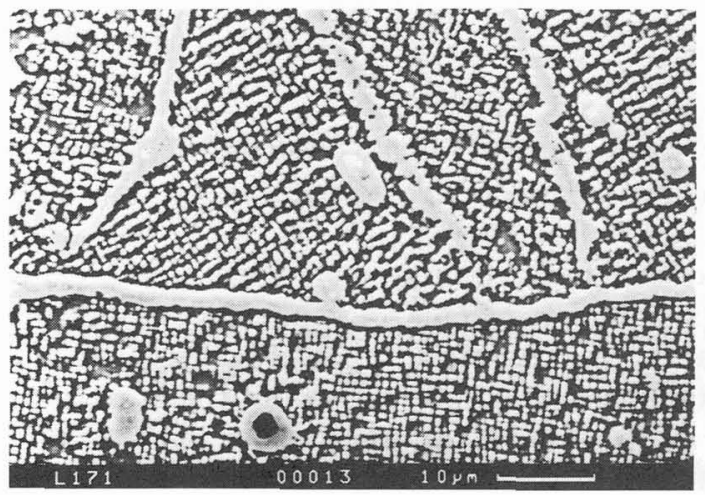

b)

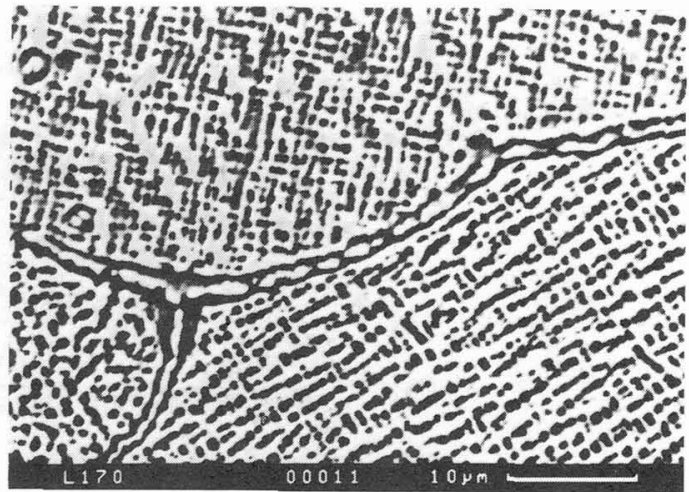

c)

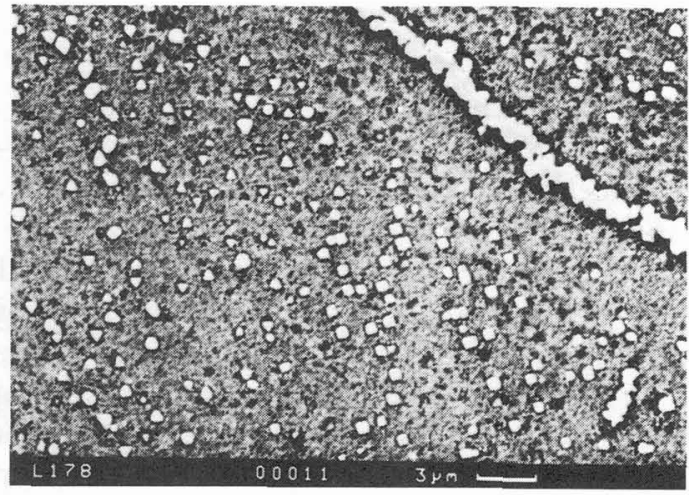

d)

Plate 2. - a) Large $\gamma^{\prime}$ particles in blade section 1 - nearest the shroud. Some possible void coalescence is also visible. b) $\gamma^{\prime}$ particles on section 2 of the turbine blade. The particles appear dark in this micrograph as marbles reagent was used. c) Large $\gamma^{\prime}$ particles on section 3 of the turbine blade. d) $\gamma^{\prime}$ particles in the "as received" nimonic 108 alloy.

3.2 CORROSION DEPOSITS ON THE TURBINE BLADE SHROUDS. - Examination in the SEM revealed considerable loss of material from the trailing edge, close to the blade shroud. Parts of this area showed a thick, friable scale, which was analysed using Energy Dispersive Analysis (EDA). EDA detected small amounts of sulphur, potassium and calcium, and significant levels of chlorine. Quantitative analysis suggested the chlorine levels to be as high as 1 weight per cent.

In plate 3, crystals which appeared to have been formed by the deposition of a "foreign species", could be seen. The analysis of them showed a high chlorine level. There was no evidence of sodium, and only very low levels of potassium or sulphur. The levels of aluminium 
were generally very low, considering the turbine blade was aluminised. Other parts of the blade tip, away from obvious areas of attack, showed higher aluminium levels.

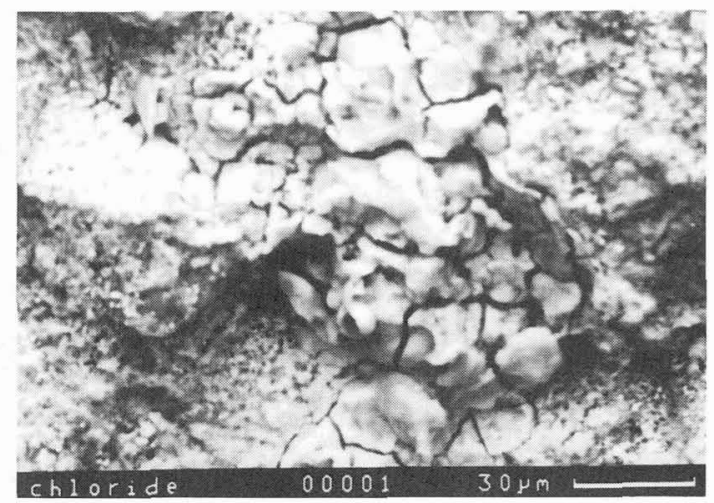

Plate 3. - Close-up of a large chlorine-containing particle close to the edge of the turbine blade platform.

3.3 CORROSION OF BLADE CROSS-SECTIONS. - Examination of blade cross-sections allowed the checking of the depth and nature of the corrosion attack, and to see if the surface aluminide coating had degraded.

Most of the examination concentrated on the section nearest to the blade shroud.

An enlarged diagram of that section is shown in figure 2. The principal features are the leading edge, the trailing edge, and the internal cooling channels.

The surface of the blade was traversed carefully, so we could see where the aluminide coating had degraded. Figure 2 suggests that much of the blade surfaces retained an integral coating of aluminide, with a two-layer structure in evidence. At some places, there was considerable attack e.g. at the leading edge (Plate 4a).

The alloy underlying this attack showed internal nitridation, which contained high levels of titanium, and aluminium.

Scanning the alloy just below this internal attack revealed a thin band of material, plus a few particles, high in sulphur (Plate $4 \mathrm{~b}$ ). The sulphur was present as chromium-rich sulphide inclusions, and must have originated from the $\mathrm{CaSO}_{4}$ in the sea salt. Sulphidation beneath oxidation has been reported by Hossain $e t a l$. as characterising hot corrosion [3]. The extent of sulphidation was very limited, however, and it should not be given too much significance. The very apex of the leading edge was also examined. The thick scale present was aluminiumrich, it too containing nitrides, as well as oxides.

3.4 INTERNAL COOLING PASSAGES. - The maximum operating temperature for a nimonic 108 turbine blade, under stress, is in the range $850-950^{\circ} \mathrm{C}$ [4]. Since the inlet temperature of the RB211 engines at St. Fergus is $1074^{\circ} \mathrm{C}$, the blade must be cooled extensively.

The cooling channels within the section nearest to the blade shroud were examined. The channel nearest the training edge of the blade, showed corrosion, plus attack of the surrounding material to a depth of 300 microns (Plate 5). Analysis of this internal attack showed 


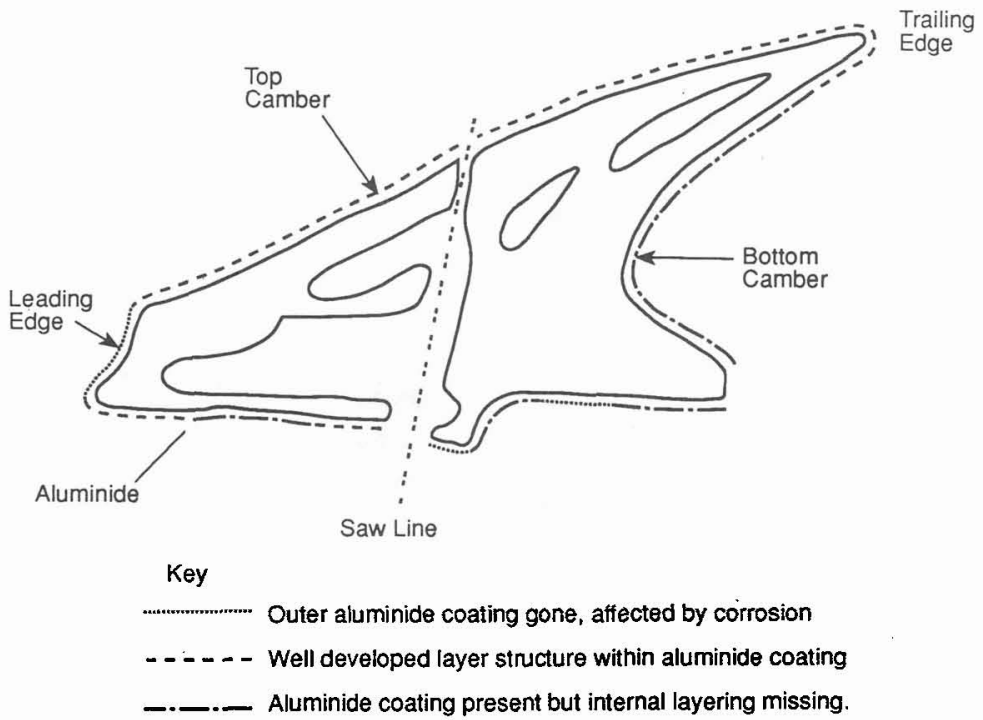

Fig. 2. - Sketch diagram of the cross-section through the turbine blade showing the distribution of the aluminide coating. The section was sawn in half during sample preparation.

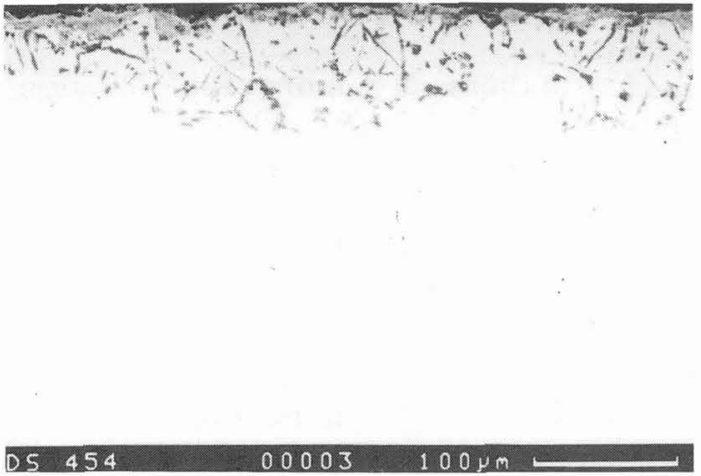

a)

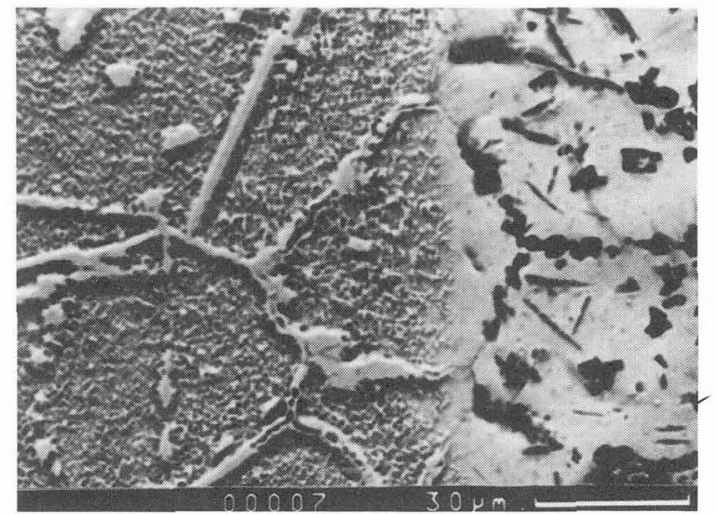

b)

Plate 4. - a) Area of attack on the surface of the blade. EDA showed a lack of aluminium to protect the blade. b) Internal attack close to the leading edge of the turbine blade. The dark-coloured, angular phase within the light band is a titanium, aluminium nitride. The grey particle with a white dot is sulphide.

angular-shaped particles, they were aluminium and chromium-rich nitrides. There was no sign of sulphur here. The high levels of corrosion, and the presence of nitrides suggest local metal temperatures around $1000^{\circ} \mathrm{C}$. 


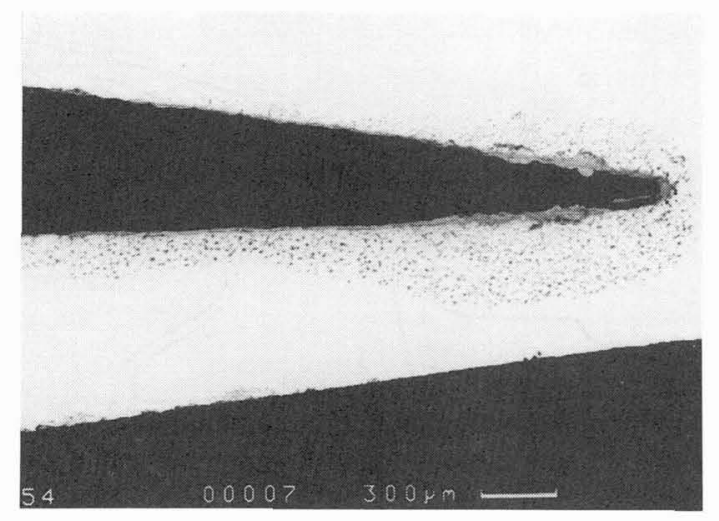

Plate 5. - Internal corrosion at the apex of the turbine blade cooling channel.

3.5 GENERAL COMMENTS ON THE CORROSION. - The main cause of the corrosion of the RB211 turbine blades was chloride. The chloride would have entered, as $\mathrm{NaCl}$, in the seasalt. Work by Belcher, Bird and Wilson [5] showed that forged nimonic 105 turbine blades were reasonably resistant to oxidation, and even sulphidation.

However, when only $1 \mathrm{ppm}$ of $\mathrm{NaCl}$ was added to the burner fuel, their turner rig tests revealed rapid corrosion of nimonic 105. However, they found that attack did not occur on new components, but only on blades aged for some time at $900^{\circ} \mathrm{C}$. An increase in the rate of attack of nimonic alloys by chloride, in this case $\mathrm{NaCl}$, with increasing temperature was noted by Hurst $e t$ al. [6].

Another component of sea-salt, $\mathrm{CaSO}_{4}$, was the cause of the small amount of sulphidation seen. Although Belcher et al. [5], has suggested sulphidation was not the problem for nimonic 105 , even very small sulphur concentrations at the grain boundaries of nimonic alloys can cause embrittlement [3].

The size of the $\gamma^{\prime}$ particles and the degradation of the aluminide coating, near the trailing edge of the blade tip, suggests that this section of the blade ran hot, thus accelerating corrosion.

The main peculiarity about the hot salt corrosion at St. Fergus was its location, the corroded area being underneath the blade shroud. The cause seems to have been the washing procedure, resulting in "baked on" salt deposits being caught underneath the blade shroud by a centrifugal action. This explains why chlorides played such a dominant part in the attack. A brief outline of the washing procedure is presented in section 4.2.

\section{Preventive measures.}

Having worked out the cause of the rapid corrosion, several preventive measures to reduce the hot salt corrosion were taken. These were :

Improvements in air filtration ;

Reduction in component temperatures ;

Changes in compressor washing procedure ;

Improvements to turbine blade coatings.

These measures are detailed below. 
4.1 AIR FILTERS AND COMPONENT TEMPERATURES. - A reduction in the amount of salt reaching the RB21l compressors would, obviously, reduce corrosion rates. The air-bag filters in use were only $85 \%$ efficient at the 5 micron dust level. A new set, which takes out $98 \%$, has since been installed. The use of louvre-type filters, as a first stage, should help to keep the bag filters drier.

The turbine manufacturers adjusted the burner nozzle angles, which has reduced blade temperatures.

4.2 CHANGES IN COMPRESSOR WASH PROCEDURE. - Before this investigation, the RB211 engines were cooled for one hour, and then washed, using a detergent recommended by the manufacturer. The compressor was run at $900 \mathrm{rpm}$ during washing. Boroscope examination showed a great deal of liquid, contrary to expectations, getting through to the turbine section. As a result, compressor wash procedure has been improved to prevent the carry over of salt.

4.3 MATERIALS AND COATINGS. - The resistance of nimonic alloys to oxidation/salt corrosion can be improved by the use of a suitable coating. Belcher et al. [5] had suggested pack aluminising as the remedy for nimonic 105 when used in aviation gas turbines. However, land-based gas turbines must run for much longer periods and, with time, an aluminide coating will degrade. Three types of coating would protect the nimonic blades more effectively.

4.3.1 Platinum aluminising. - Platinum aluminising has been shown to be more protective to nimonic alloys than conventional aluminide coatings. Platinum modified coatings have a layer of $\mathrm{PtAl}_{2}$, but this is not always continuous. Nevertheless, Meier found that these coatings gave protection in a number of critical environments [7]. He found improvements on samples exposed to isothermal hot corrosion at $700^{\circ} \mathrm{C}$ (Type II attack).

4.3.2 CoCrAlY coatings. - The plasma-sprayed CoCrAlY coatings look promising, especially as they are resistant to marine conditions. The problem with these coatings, however, is the level of chromium. Overlay CoCrAlY coatings with 25 weight per cent chromium perform well at high temperatures, but less well in low temperature hot corrosion conditions. Raising the chromium content to 30 weight per cent can improve low temperature resistance, but is detrimental to corrosion resistance at higher temperatures [8].

4.3.3 Silicon aluminium coatings. - Another possible solution to the hot corrosion problem is silicon aluminising. Considerable research was carried out on such coatings at RAE Pyestock, by Restall and Wood. They found "Sermalloy J" to be resistant both to high and low temperature hot corrosion. It is widely used on marine gas turbines [8]. Sermalloy J can be applied easily even on "stripped" turbine blades.

\section{Discussion and conclusions.}

The investigations of the corrosion at St. Fergus shows that the problem could not be ascribed to one simple cause. Air filtration, compressor washing procedures, high temperatures and blade materials, all contributed to the development of hot salt corrosion.

Although this report is confined to the RB211, this problem is not specific to this engine. The problem of salt contamination and carry-over seems to become more significant the higher the inlet temperatures and more intricate the blade cooling. The Avons at St. Fergus do not suffer from this problem. 
Since no filtration system can remove all incoming particles, this type of attack could cause corrosion and overheating of any gas turbines with an intricate blade cooling design.

The most significant finding of this work is that salt contamination from coastal atmosphere is a potential hazard in the U.K. The problem may not be significant in many other parts of the world. On North Sea production platforms, however, sea-water corrosion is of real concern, and up to three stages of filtration are used. High quality blade coatings are also prescribed.

Even on inland sites in the U.K., a reasonable distance away from the sea, there may be problems with open cycle machinery. Lloyd and Manning found that salt can be carried by even normal weather, up to $15 \mathrm{~km}$ inland, and much further during severe storms [9].

Many of the gas-fuelled power plant currently under construction in the U.K. are sited close to the coast. The operators of such plant should be acquainted with the dangers of salt corrosion, and the necessary preventive measures.

\section{Acknowledgements.}

To British Gas plc for permission to publish this paper. To their colleagues at LRS, who helped with this investigation, especially Dr. S.E. Cook.

\section{References}

[1] Page K., Taylor R.J., Deposition and Corrosion in Gas Turbines, A.B. Hart, A.J.B. Cutler Eds. (Applied Science, 1973).

[2] Betteridge W., Heslop J., The Nimonic Alloys, 2nd Ed. (Edward Arnold, 1974) Pp. 80-82.

[3] Hossain M.K., RhodeS-Brown J.E., SAunders S.R.J., The Behaviour of High Temperature Alloys in Agressive Environments (The Metals Society, Petten, 1979).

[4] Gas Turbine World 1990 Handbook: Gas Turbine World, Vol. 12 (Pequot Publications, 1990).

[5] BELCHER P.R., BIRD R.J., WILSON R.W., Hot Corrosion problems associated with Gas Turbines (ASTM, 1967).

[6] Hurst R.C., Johnson J.B., Davies M., Hancock P., Deposition and Corrosion in Gas Turbines, A.B. Hart, A.J.B. Cutler Eds. (Applied Science, 1973).

[7] MEIER G., European Colloquium on the rôle of active elements in High Temperature Alloys (Petten, Netherlands, 1988).

[8] RESTALL J.E., WOOD M.I., Ind. Corros. (7) (1989).

[9] Lloyd B., Manning M.I., Corros. Sci. 30 (1) (1990). 